Bull. Mater. Sci., Vol. 14, No. 4, August 1991, pp. 1093-1100. (C) Printed in India.

\title{
Oxide glass filaments and their superconducting phase by annealing
}

\author{
B K CHAUDHURI and K K SOM \\ High Temperature Superconductivity Laboratory, Indian Association for the Cultivation of \\ Science, Calcutta 700032, India.
}

\begin{abstract}
Bi}_{4} \mathrm{Ca}_{3} \mathrm{Sr}_{3} \mathrm{Cu}_{x} \mathrm{O}_{y}$ (4334) oxide glasses with different concentrations of the transition metal copper have been prepared by rapid quenching technique from respective melts. These'glasses have been characterized from electrical, magnetic, dielectric and other properties. The semiconducting glasses are not superconducting even down to $4 \cdot 2 \mathrm{~K}$. However, by properly annealing the glasses in air or in oxygen atmosphere they can be converted into the corresponding superconducting phases with superconducting transition temperatures between 70 and $110 \mathrm{~K}$ depending on the $\mathrm{Cu}$ ion concentrations. The dc conductivity of the glasses could be explained with small polaron adiabatic hopping mechanism. Analysis shows that the correlated barrier hopping (CBH) mechanism is the most appropriate model for explaining the a.c. conductivities of these glasses. Addition of a small amount (about $2 \mathrm{wt} \%$ ) of $\mathrm{B}_{2} \mathrm{O}_{3}$ makes it possible to draw glass filaments which could also be converted into the superconducting phase with $T_{4}$, values lower than those obtained from the respective pure glasses.
\end{abstract}

Keywords. Glass-ceramic route; high temperature superconducting filaments; oxide glass filaments.

\section{Introduction}

First report on the novel method of making superconducting oxide (HITSO) like $\mathrm{Y}_{1} \mathrm{Ba}_{2} \mathrm{Cu}_{3} \mathrm{O}_{x}$ (123) using glass to ceramic route (GCR) was made by Komatsu et al (1987) and subsequentiy several reports have been made (Chaudhuri et al 1989a; Som and Chaudhuri 1990) describing the preparation and characterization of many other HITSO materials prepared by the GCR technique. Since the HITSO thus prepared are very dense, and since it is convenient to make HITSO wires or tapes from the glass phase, the GCR technique is popular (Som and Chaudhuri 1990). The microstructures of these glasses could be well controlled and the crystallites in a particular orientation can be aligned when one starts making HITSO using GCR method. Recently we prepared $\mathrm{Y}-\mathrm{Ba}-\mathrm{Cu}-\mathrm{O}, \mathrm{Y}-\mathrm{Ba}-\mathrm{Sr}-\mathrm{Cu}-\mathrm{O}, \mathrm{Bi}-\mathrm{Sr}-\mathrm{Ca} \mathrm{Cu}-\mathrm{O}$ and $(\mathrm{Bi}, \mathrm{Pb})-\mathrm{Ca}-\mathrm{Sr}-\mathrm{Cu}-\mathrm{O}$ type HITSO materials using the GCR technique. In the present paper, however, we report the electrical, magnetic, dielectric and other properties of the $\mathrm{Bi}_{4} \mathrm{Sr}_{3} \mathrm{Ca}_{3} \mathrm{Cu}_{y} \mathrm{O}_{x}$ (4334) system for different values of transition metal (Cu) ion (TMI) concentrations (for $y=3-5$ ). Attempt has also been made to make glass filaments and then convert them to the corresponding superconducting phase by properly annealing the glass filaments. A major problem for the preparation of $\mathrm{Bi}-\mathrm{Sr}-\mathrm{Ca}-\mathrm{Cu}-\mathrm{O}$ oxide glass fibres is the devitrification of the melts before drawing fibres from the melt. This problem was partially solved by adding $\mathrm{B}_{2} \mathrm{O}_{3}$ as glass former and varying the concentration of bismuth oxide in the glass. Since addition of $\mathrm{B}_{2} \mathrm{O}_{3}\left(\sim 2 \mathrm{wt} \%\right.$ ) reduces the $T_{c}$ values (for instance for the 4334 glasses) to about $75 \mathrm{~K}$, we report in this paper the properties of the samples without $\mathrm{B}_{2} \mathrm{O}_{3}$. 


\section{Experimental}

For making the (4334), (2223) etc. glasses $\mathrm{Bi}_{2} \mathrm{O}_{3}, \mathrm{SrCO}_{3}, \mathrm{CaCO}_{3}$ and $\mathrm{CuO}$ oxides were mixed well in suitable proportion. The mixed oxides were melted at $1200^{\circ} \mathrm{C}$ for $2 \mathrm{~h}$, the melt quickly quenched as discussed earlier (Som and Chaudhuri 1990) and thin glass plates were made. The amorphous character of the glasses with different copper concentrations were tested by X-ray diffraction and SEM studies. The amorphous nature of one of the samples is shown in figure 1 . The $\mathrm{CuO}$ concentration dependences of density of the glasses are shown in figure 2 . The glass transition temperatures (ranging from $400-450^{\circ} \mathrm{C}$ ) and the crystallization temperatures were obtained by differential thermal analysis.

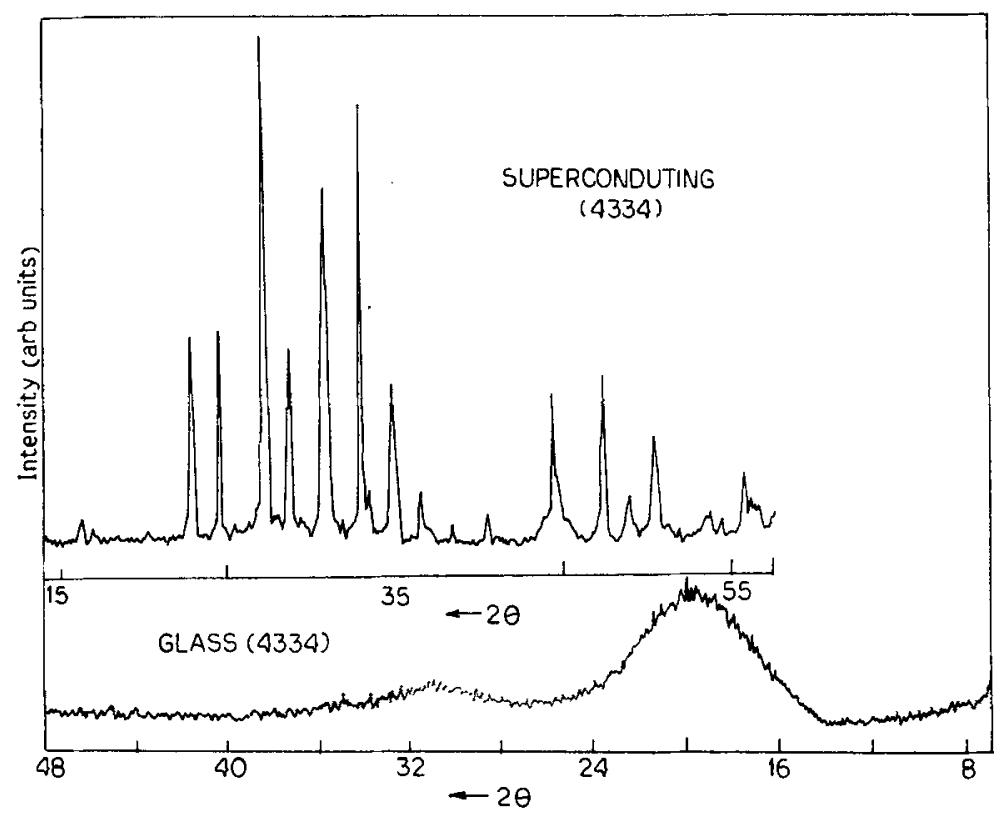

Figure 1. X-ray diffractograms of amorphous and crystalline phases of a particular sample.

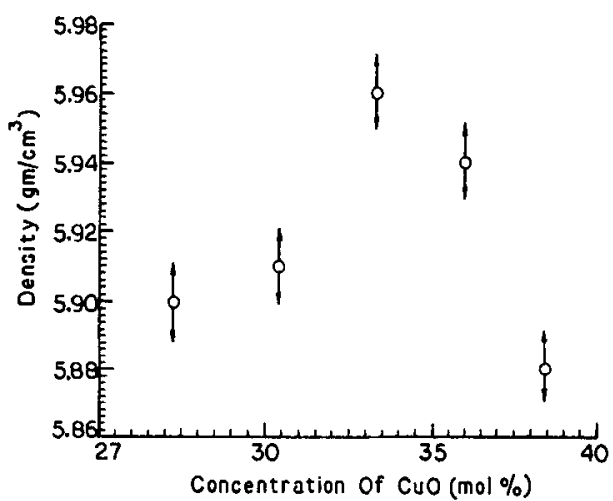

Figure 2. Variation of density with concentration of $\mathrm{CuO}$. 


\subsection{Preparation of glass filaments}

The oxide glass filaments were made by two techniques: (i) by pouring the melt through capillary tubes of silver and ceramics and removing the silver tubes or breaking the ceramic (or fused silica) tubes; (ii) by melting the (4334)-type glasses with appropriate quantity of $\mathrm{B}_{2} \mathrm{O}_{3}$ and drawing small fibres or tapes by melt-spinning technique. For a proper choice of $\mathrm{B}_{2} \mathrm{O}_{3}$ and $\mathrm{Bi}$ concentrations in the glass it is necessary to draw filaments of the glass and then annealing the filaments into the superconducting phase. This technique, though convenient, reduces the superconducting transition temperature $T_{c}$ and increases the resistivity of the samples.

\section{Properties of glasses}

The electrical conductivity $\left(\sigma_{\mathrm{dc}}\right)$ of the glasses at a fixed temperature $(300 \mathrm{~K})$ for different $\mathrm{CuO}$ concentrations is shown in figure 3 . It is seen that d.c. conductivity increases with increase of transition metal ion concentrations. The thermal variations of electrical conductivities of different glasses (figure 4) are consistent with the d.c. conductivity derived on the basis of the hopping of polarons in the adiabatic

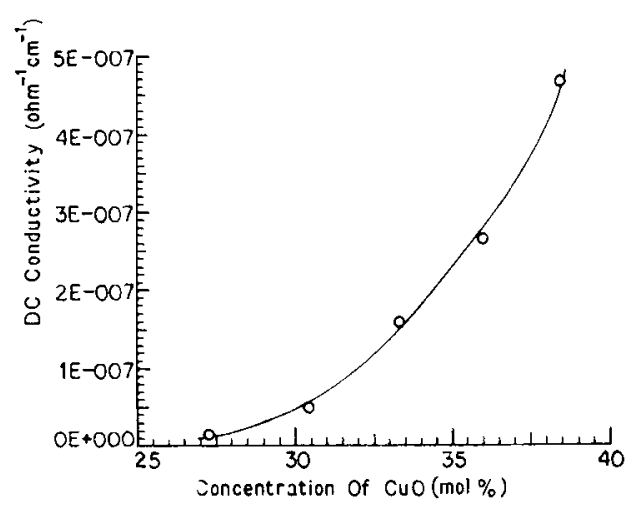

Figure 3. Variation of d.c. conductivity of the glasses with $\mathrm{CuO}$ concentration.

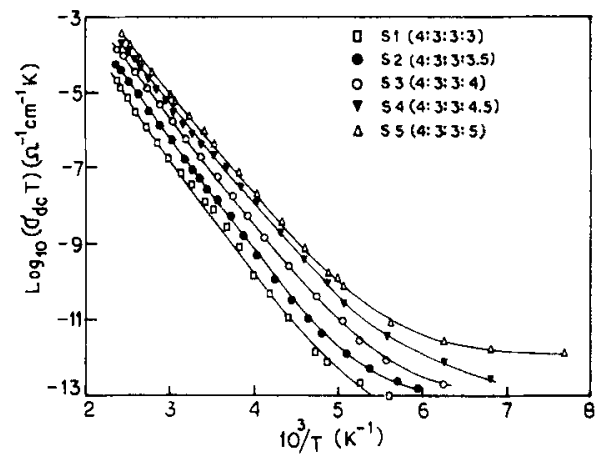

Figure 4. Thermal variation of d.c. conductivity of the glasses. 
Table 1. Different physical parameters of the $\mathrm{Bi}-\mathrm{Sr}-\mathrm{Ca}-\mathrm{Cu}-\mathrm{O}$ glass.

\begin{tabular}{|c|c|c|c|c|c|}
\hline Samples & S1 & S2 & S3 & $\mathrm{S} 4$ & S5 \\
\hline $\begin{array}{l}\text { Composition } \\
\text { (Bi:Sr:Ca:Cu) }\end{array}$ & $(4: 3: 3: 3)$ & $(4: 3: 3: 3 \cdot 5)$ & $(4: 3: 3: 4)$ & $(4: 3: 3: 4 \cdot 5)$ & $(4: 3: 3: 5)$ \\
\hline $\begin{array}{l}\text { Starting } \mathrm{Cu} \\
\text { content }\left(\mathrm{wt}^{\circ} \% \text { ) }\right. \\
\text { Final } \mathrm{Cu}\end{array}$ & 11.55 & $13 \cdot 16$ & 14.70 & $16 \cdot 16$ & $17 \cdot 56$ \\
\hline content $(w t \%)$ & $11 \cdot 64$ & - & 15.90 & - & $18 \cdot 08$ \\
\hline$N\left(10^{21} \mathrm{eV}^{-1} \mathrm{~cm}^{-3}\right)$ & 6.52 & $7 \cdot 48$ & $8 \cdot 44$ & $9 \cdot 24$ & 9.92 \\
\hline$\rho\left(\mathrm{g} \mathrm{cm}^{-3}\right)$ & $5 \cdot 90$ & $5 \cdot 91$ & 5.96 & $5 \cdot 94$ & $5 \cdot 88$ \\
\hline$\beta=\mathrm{Cu}^{+} / \mathrm{Cu}_{\mathrm{tot}}$ & $0 \cdot 84$ & $0 \cdot 81$ & $0 \cdot 87$ & $0 \cdot 86$ & $0 \cdot 85$ \\
\hline$R(\AA)$ & $5 \cdot 35$ & $5 \cdot 11$ & 4.91 & $4 \cdot 77$ & $4 \cdot 66$ \\
\hline$r_{p}(\AA)$ & $2 \cdot 16$ & $2 \cdot 06$ & 1.98 & 1.92 & 1.88 \\
\hline$W$ at $250 \mathrm{~K}$ & 0.566 & 0.542 & 0.521 & 0.503 & 0.480 \\
\hline$W$ at $400 \mathrm{~K}$ & 0.698 & 0.674 & 0.646 & 0.627 & 0.615 \\
\hline$v_{0}\left(10^{12} \mathrm{~Hz}\right)$ & $9 \cdot 16$ & $8 \cdot 54$ & $8 \cdot 12$ & $8 \cdot 00$ & $7 \cdot 75$ \\
\hline$\alpha\left(\AA^{-1}\right)$ & $1 \cdot 23$ & $1 \cdot 03$ & $0 \cdot 97$ & 0.75 & 0.87 \\
\hline$x(\text { at } 300 \mathrm{~K})^{*}$ & 13.5 & -- & 13.6 & $14 \cdot 2$ & $14 \cdot 5$ \\
\hline
\end{tabular}

*Estimated from the Cole-Cole plot of dielectric constant data (Chaudhuri and Som, unpublished).

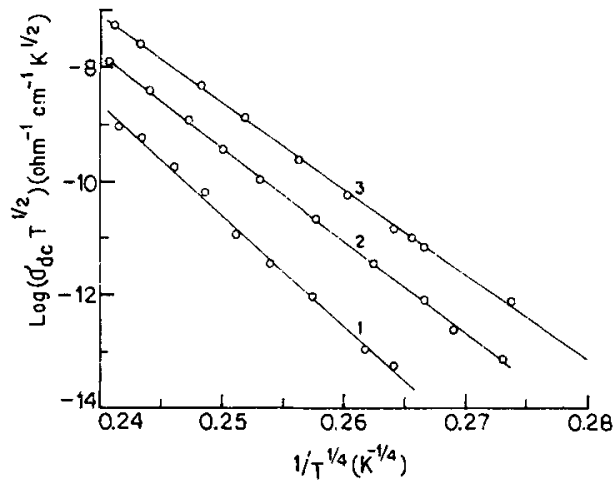

Figure 5. $T^{-1 / 4}$ versus $\log \left(\sigma_{\mathrm{d} . \mathrm{c}} T^{1 / 2}\right)$ plot for three glass samples.

approximation (Austin and Mott 1969) and given by

$$
\sigma_{\mathrm{dc}}=\frac{{ }_{\mathrm{ph}} N e^{2}}{k_{B} T} C(1-C) \exp (-2 \alpha R) \exp \left(-W i k_{B} T\right)
$$

where $v_{\mathrm{ph}}$ is the phonon frequency, $N$ the number of TMI sites per unit volume, $R$ the average TMI site spacing, $C$ and $\alpha$ are, respectively, the ratio of TMI concentration in the low valency state to the total TMI concentration and the wave vector decay constant. The different parameters of the model obtained by fitting with the experimental data are shown in table 1. Mott's $T^{-1 / 4}$ analysis for the variable range hopping (VRH) in the low-temperature regime was found to be not suitable for the glasses. On the other hand, Greaves' expression (Greaves 1973) for variable range hopping in the intermediate temperature regime which gives $\sigma_{\mathrm{dc}} T^{1 / 2}=A \exp$ $\left(-B / T^{1 / 4}\right)$ with $B=2 \cdot 1\left[\alpha^{3} / k_{B} N\left(E_{F}\right)\right]^{1 / 4}$ seems to be applicable for the glasses. The 
$T^{-1 / 4}$ versus $\log \left(\sigma_{\mathrm{dc}} T^{1 / 2}\right)$ plot is shown in figure 5. The variation of activation energy $W$ with TMI $(\mathrm{Cu})$ concentration is shown in figure 6 .

The a.c. conductivity (figure 7) of the glasses can be written as

$$
\sigma_{\mathrm{ac}}=\sigma_{\mathrm{fotal}}(\omega)-\sigma_{\mathrm{dc}}
$$

The frequency dependence of a.c. conductivity obeys the general behaviour of the amorphous glasses viz.

$$
\sigma_{\mathrm{ac}}(\omega)=A \omega^{\mathrm{s}}
$$

However, the correlated barrier hopping ( $\mathrm{CBH})$ model for a.c. conductivity of amorphous glasses proposed by Pike (1972) and Elliott (1977) was best suited for the present semiconducting glass system. The most general formula for the conductivity obtained from the $\mathrm{CBH}$ model is given by

$$
\sigma_{\mathrm{ac}}=\frac{1}{24} \pi^{3} N^{2} \varepsilon_{0} \varepsilon R_{(\%)}^{\circ}
$$

where $\varepsilon_{0}$ and $\varepsilon$ are the permittivity of the free space and the dielectric constant of the

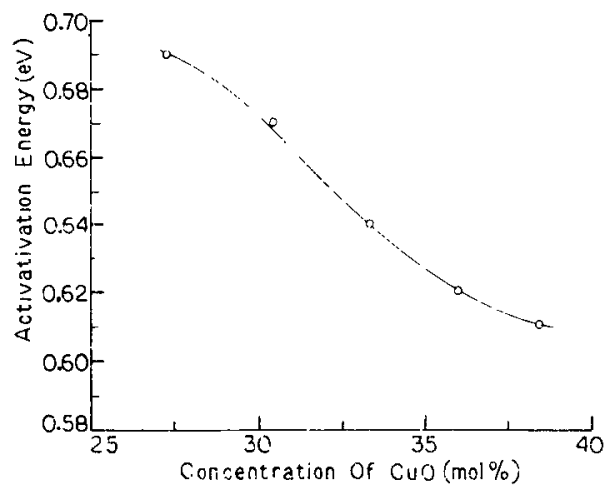

Figure 6. Concentration $(\mathrm{CuO})$ dependences of activation energy.

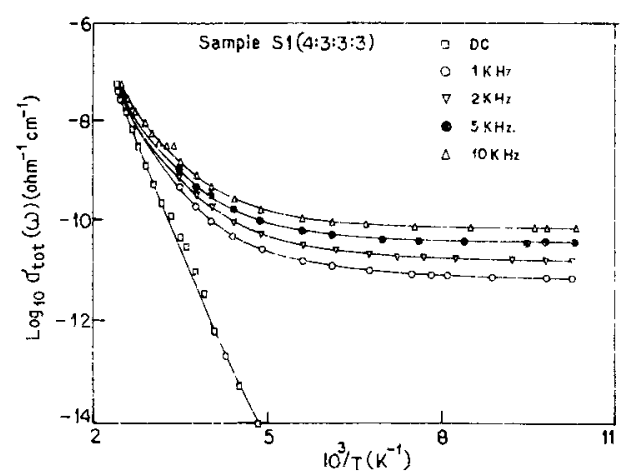

Figure 7. Thermal variation of a.c. conductivity of a typical glass sample at different. frequencies 
sample respectively. The average hopping distance $R_{\omega}$ is given by

$$
R_{\omega}=\left(2 e^{2} / \pi \varepsilon_{0} \varepsilon\right)\left[W_{M}+k_{B} T \ln \left(1 / \omega \tau_{0}\right)\right],
$$

where $W_{M}$ is the barrier height. The model parameters calculated with this equation are shown in table 1 .

3.1 Electrical conductivity and magnetic susceptibility of the superconducting phase

The d.c. electrical conductivity of the heat-treated (at $850^{\circ} \mathrm{C}$ for $24 \mathrm{~h}$ in air) superconducting samples (both pellets or filaments) was measured by the standard

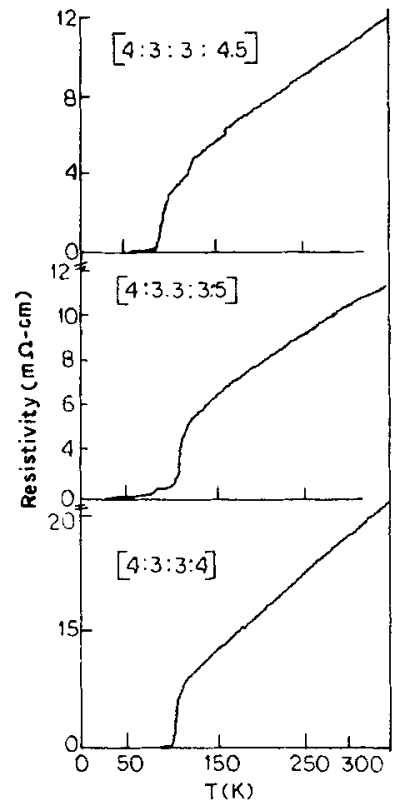

Figure 8. Thermal variation of resistivity of the superconducting phase obtained by annealing the glass.

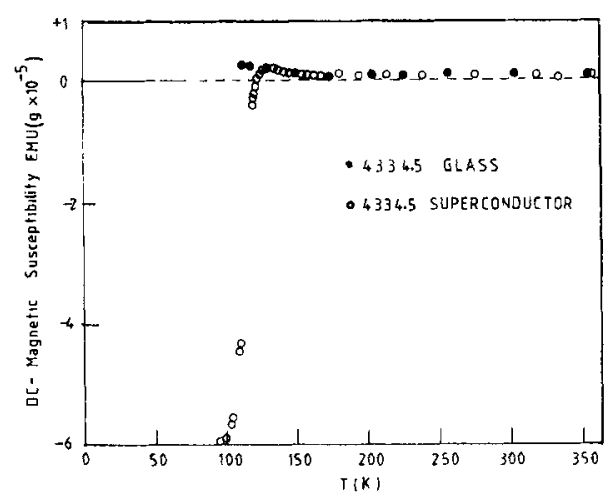

Figure 9. Magnetic susceptibility of glass and its corresponding superconducting phase. 


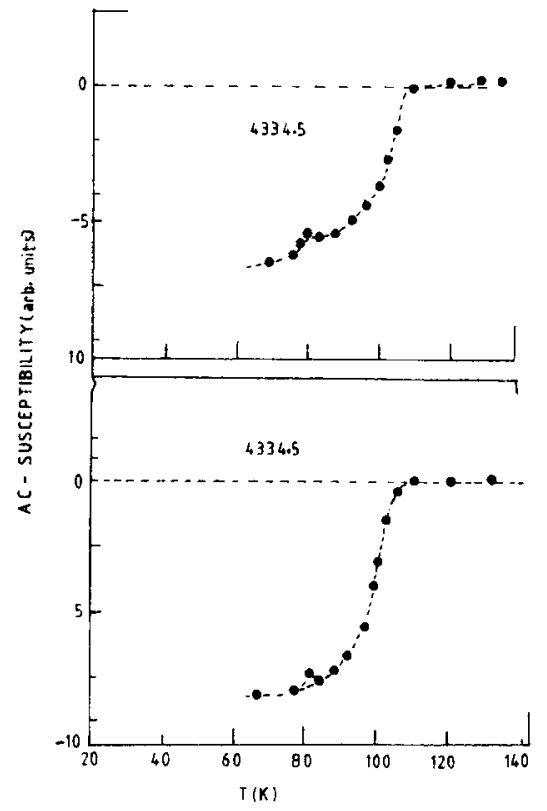

Figure 10. Thermal variations of the a.c. magnetic susceptibility of some superconductors obtained from the glass phases.

four-probe method in the temperature range of 77 to $300 \mathrm{~K}$. The X-ray diffraction pattern of one of the samples after being annealed is shown in figure 1. The plot of electrical resistivity as a function of temperature is shown in figure 8 showing $T_{c}$ around $85 \mathrm{~K}$. The corresponding d.c. magnetic susceptibilities of the glass and superconducting sample are shown in figure 9 . Both from the thermal variations of electrical resistivity and magnetic susceptibility the superconducting behaviour of the samples can be well visualized (figure 10).

\section{Conclusion}

The transition metal oxide glasses like $\mathrm{Bi}_{4} \mathrm{Sr}_{3} \mathrm{Ca}_{3} \mathrm{Cu}_{x} \mathrm{O}_{y}(x=3-5)$ behave almost similarly with other transition metal oxide glasses as $\mathrm{V}_{2} \mathrm{O}_{5}-\mathrm{P}_{2} \mathrm{O}_{5}$ (Sayer and Mansingh 1972), $\mathrm{V}_{2} \mathrm{O}_{5}-\mathrm{Bi}_{2} \mathrm{O}_{3}$ (Ghosh and Chaudhuri 1986), $\mathrm{Bi}_{2} \mathrm{O}_{3}-\mathrm{Fe}_{2} \mathrm{O}_{3}$ (Chaudhuri et al 1989b) etc which do not become superconducting unlike (4334) glasses. The addition of $\mathrm{B}_{2} \mathrm{O}_{3}$ glass-forming oxides appears to be suitable for various technological applications.

\section{References}

Austin I G and Mott N F 1969 Adv. Phys. 1841

Chaudhuri B K, Som K K and Sengupta S P 1989a J. Mater. Sci. Lett. 8520

Chaudhuri B K, Chaudhuri K and Som K K 1989b J. Phys. Chem. Solids 501137

Elliott S R 1977 Philos. Mag. 361291

Ghosh A and Chaudhuri B K 1986 J. Non-Cryst. Solids 83151 
Greaves G N 1973 J. Non-Cryst. Solids 11427

Komatsu T, Imai K, Matusita K, Takata M, Iwai Y, Kawakami A, Kaneko Y and Yamashita T 1987 Jpn J. Appl. Phys. 26 L1148

Pike G E 1972 Phys. Rev. B6 1572

Sayer M and Mansingh A 1972 Phys. Rev. B6 4629

Som K K and Chaudhuri B K 1990 Phys. Rev. B41 1581 